\title{
IMPACTOS AMBIENTAIS NA ÁREA DE PROTEÇÃO AMBIENTAL(APA) DE GUARATUBA, PARANÁ, BRASIL, SOB O PONTO DE VISTA DE MORADORES TRADICIONAIS
}

\section{Environmental impacts in the Environmental Protection Area (APA) of Guaratuba, State of Paraná, Brazil: the traditional communities point-of-view}

Raphael Telles Kantek

Mestre em Gestão Ambiental pela Universidade Positivo Curitiba/PR - Brasil fkantek@up.edu.br

Klaus Dieter Sautter Doutor em Engenharia Florestal pela Universidade Federal do Paraná Professor da Universidade Positivo Curitiba/PR - Brasil ksautter@up.edu.br

Mário Sérgio Michaliszyn Doutor em Ciências Sociais pela Pontifícia Universidade Católica de São Paulo Professor da Universidade Positivo Curitiba/PR - Brasil mario@up.edu.br

Artigo recebido para publicação em 16/03/09 e aceito para publicação em 13/07/09

RESUMO: A pesquisa foi realizada na Área de Proteção Ambiental (APA) de Guaratuba, Paraná, e teve como objetivo analisar os impactos ambientais sob o ponto de vista dos moradores tradicionais locais. Utilizou-se dois instrumentos: Sistema de Informações Geográfica (SIG) e Discurso do Sujeito Coletivo (DSC). Embora o SIG contenha mais situações que no DSC, observou-se que são coincidentes. A forma como as pressões atuam é complexa e a análise deve envolver as comunidades naturais e tradicionais.

Palavras-chave: APA de Guaratuba. Sistemas de Informações Geográficas. Impactos Ambientais. Populações Tradicionais.

ABSTRACT: The present research was carried out in the Environmental Protection Area (APA) of Guaratuba, State of Paraná, to analyze the environmental impacts of the APA as assessed by the local traditional communities. Two instruments were used: Geographical Information System (GIS) and Discourse of the Collective Subject (DSC). Although the GIS covers more situations that the DSC, results were similar. The pressures are complex and the analysis must involve the natural and traditional communities.

Keywords: Environmental Protection Area of Guaratuba. Geographical Information System. Environmental impacts. Traditional communities. 


\section{INTRODUÇÃO}

A Floresta Atlântica é um ecossistema rico em biodiversidade que ocorre em áreas que podem assumir um isolamento devido às condições geo-climatológicas. Este isolamento propicia à evolução natural das espécies a possibilidade de endemismo, o que torna a Floresta Atlântica ainda mais importante por apresentar regiões com espécies não existentes em qualquer outro lugar do globo. Existente somente no Brasil, a Floresta Atlântica é a segunda floresta mais ameaçada no mundo (CONSELHO NACIONAL DE PESQUISA - CNPq, 2001; WORLD WILDLIFE FUND - WWF, 2006).

A história da Floresta Atlântica mostra uma sobrevivência dramática, que desde a colonização européia teve de enfrentar desafios de perpetuação. Os desafios que o meio ambiente enfrentou e ainda enfrenta se manifestam como impactos ambientais, muitas vezes ocasionados pela ação do ser humano, considerando-se, assim, o evento danoso ao ambiente como pressão antrópica (CONSELHO NACIONAL DE PESQUISA - CNPq, 2001).

A pressão no ecossistema exercida pelas comunidades tradicionais é insignificante se comparada com a pressão que as grandes empresas, como por exemplo, o setor madeireiro no Brasil, que por muito tempo se baseou no extrativismo sem o uso sustentável da matéria-prima. Como conclusão do processo insustentável, a crescente demanda de matéria-prima pelas indústrias madeireiras levou à ocorrência de plantios florestais homogêneos, arrasando os ecossistemas existentes (MLYNARZ, 2004).

A demanda constante de matéria-prima seja para as carvoarias ou madeireiras, ou como reivindicação uso do solo para o plantio pelos latifúndios, age como um fator degradante que reduz as áreas naturais. O resultado é que as áreas naturais estão diminuindo, a ponto de se tornar preocupante a pressão causada pelas comunidades campesinas que realizam o extrativismo ancestral de subsistência na Floresta Atlântica.
Este trabalho teve como objetivo diagnosticar, com o uso de ferramentas multidisciplinares (SIG Sistema de Informações Geográficas- e DSC - Discurso do Sujeito Coletivo), os impactos ambientais sobre a cobertura vegetal da APA de Guaratuba.

\section{METODOLOGIA}

O presente trabalho foi realizado na APA(Área de Proteção Ambiental) de Guaratuba, que possui cerca de 199.586,51 hectares, representando aproximadamente $1 \%$ do território paranaense. Sua extensão abrange os municípios de Guaratuba, Matinhos, Paranaguá, Tijucas do Sul e São José dos Pinhais (FIG. 1), situada nas unidades fisiográficas: Planície Litorânea, Serra do Mar e Primeiro Planalto. Localiza-se geograficamente entre as coordenadas de latitudes

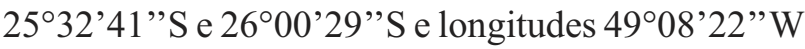
e 48 32'18”'W (SILVEIRA et al., 2005).

Foram utilizadas ferramentas multidisciplinares para analisar impactos e a qualidade ambiental ocorridos na cobertura vegetal da APA de Guaratuba - PR, bem como, a relação da população que ali reside com o meio ambiente. Para tanto, utilizou-se de um instrumento de análise denominado por Lefévre e Lefévre (2003) como o Discurso do Sujeito Coletivo (DSC), ou seja, um estudo construído a partir de duas figuras metodológicas: a descrição do sentido dos depoimentos, revelando as maneiras sintéticas, precisas e fidedignas de cada discurso analisado (Idéias centrais - IC) e de cada conjunto homogêneo de Expressões-chave (ECH). O Discurso do Sujeito Coletivo caracteriza-se como uma breve representação de uma série de características apresentadas pelo entrevistado e que compõem o caráter coletivo presente no pensamento de cada individuo. Como instrumento de coleta de dados foi utilizado um questionário elaborado em núcleos de perguntas dispostas de forma temporal, com uma trajetória de extração do conhecimento, que relata do passado, seguindo para o presente e, por final, o futuro. Esses núcleos foram criados com o objetivo de dispersar o conhecimento do entrevistado possibilitando que este explicite sua relação com determinada situação. Seguem os 19 núcleos utilizados no presente estudo: Caracterização do morador tradicional, Contexto his-

Sociedade \& Natureza, Uberlândia, 21 (2): 39-56, ago. 2009 


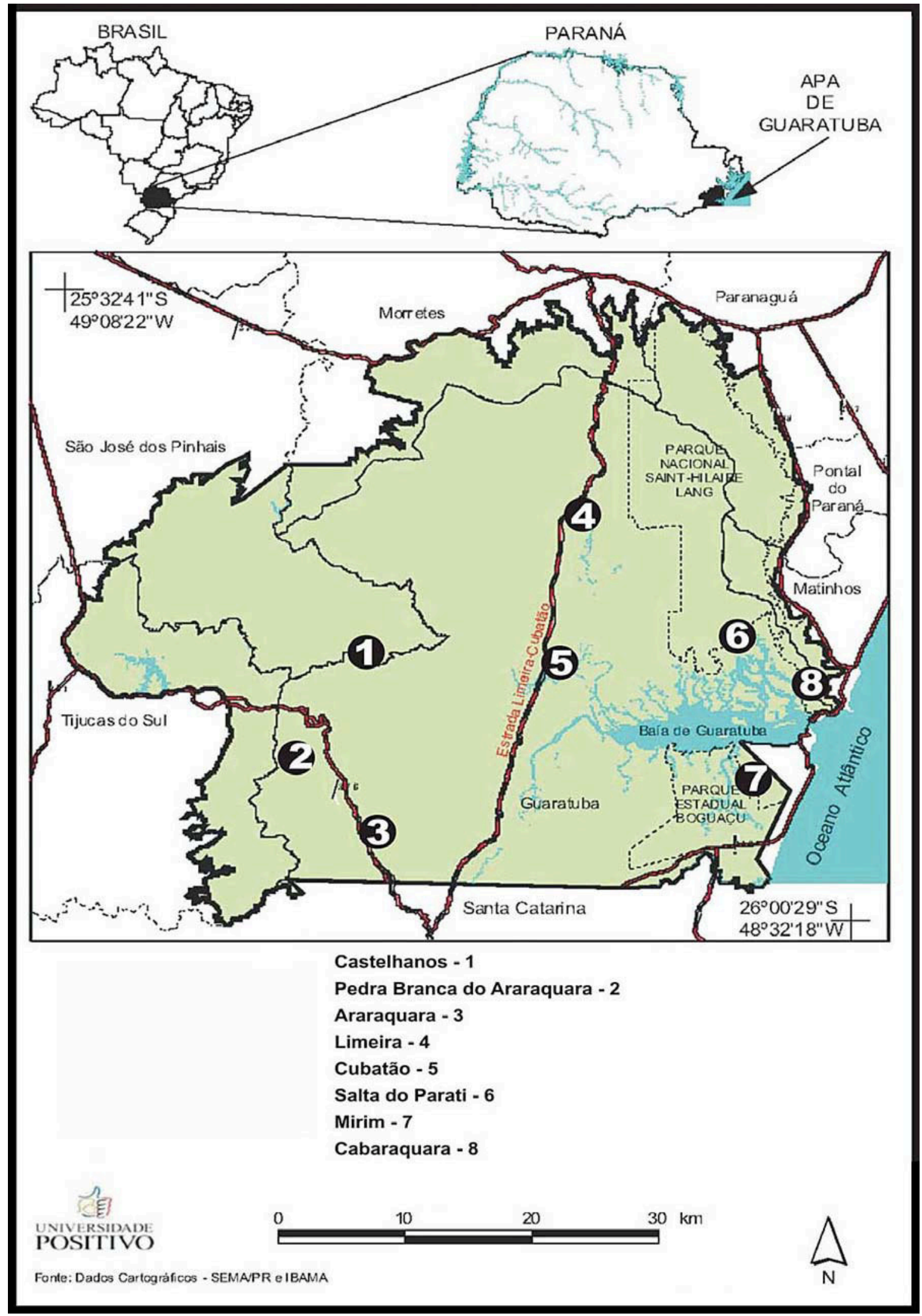

FIGURA 1. Localização da APA de Guaratuba, PR, e suas comunidades tradicionais. Adaptado de SILVEIRA et al. (2005). 
tórico, Consciência ambiental, Caça (fauna), Flora, Palmito-jussara, Cacheteira ou Cacheta, Recurso hídrico potável, Ictiofauna, Agronegócio, Criação de gado, Esgoto, Lixo, Aspectos governamentais, Conhecimento popular, APA, IBAMA, IAP, Polícia Florestal.

Os núcleos foram definidos após a realização de entrevistas informais com a população da região. Utilizando quantidade amostral, foi possível realizar a construção dos DSCs. Foram entrevistados moradores tradicionais da APA de Guaratuba, da região de serra e da região litorânea, residentes no local há mais de 20 anos e cujos ancestrais também residiram na região. Foram entrevistados moradores de região serrana (Colônias Cubatão e Castelhanos) e moradores de região litorânea (Colônia Cabaraquara), totalizando, quatro construções de discursos coletivos, baseados em entrevistas com a população. As entrevistas foram gravadas e transcritas, e a análise, bem como a construção (síntese) dos discursos baseou-se nas idéias centrais de cada pergunta, selecionando-se as expressõeschave que representam conteúdos de caráter subjetivo existente nos entendimentos e manifestações de cultura, conhecimento, atitudes, condutas, envolvimento, maneiras de pensar e atuar, opiniões, sentimentos e ações dessas coletividades, abordadas nos núcleos dos questionários com os referenciais teóricos que embasam a pesquisa.

É conveniente lembrar que o DSC é uma estratégia de analise adotada pelo pesquisador e tem como propósito sistematizar o conjunto de discursos coletados qualitativamente ao longo da pesquisa. Deste modo, os discursos sistematizados pelo pesquisador apresentam a essência do pensamento coletivo do grupo, presente nas diferentes falas dos entrevistados.

O SIG, que teve como intuito detectar os impactos ambientais de origem antropogênica na APA de Guaratuba, foi construído a partir de imagens de satélite que foram obtidas do programa de compartilhamento de bases digitais do convênio GEOM (Núcleo de Geomática da Universidade Positivo) e Engesat. Capturadas em 2002, as imagens foram fornecidas pelo satélite Landsat 7 e foram visualizadas em composição de cores RGB (Red [vermelho], Green [verde],
Blue [azul]) no programa ENVY 3.5, que processa os dados georreferenciados.

Para a fase de campo, utilizaram-se quatro mapas, preliminares, com variação de cores em composição colorida, para comparação de informações. Os dados espaciais obtidos por meio do Sensoriamento Remoto (SR) recebem colorações específicas segundo uma determinada reflectância e de maneira a orientar e auxiliar a pesquisa, é necessário que sejam cartografados. Para tanto, utilizou-se do programa Arcmap.

A pesquisa pretendeu analisar a existência de uma dualidade, das informações provenientes, da coleta de dados SIG e DSC e, a partir do estudo, apresentar os impactos ambientais na região, sob a ótica dos moradores tradicionais. Os dados obtidos a partir da formação do DSC, associados aos dados obtidos pelo SIG (Sistema de Informações Geográficas) manifestam uma forma mais apurada de compreensão do estado real das condições ambientais, exercido pela alta pressão antrópica refletida nos diferentes impactos ambientais identificados.

\section{A FLORESTA ATLÂNTICA E AS ÁREAS DE PROTEÇÃO AMBIENTAL (APA)}

Existente somente no Brasil, a Floresta Atlântica, é uma unidade fitogeográfica que apresenta os maiores agrupamentos de vida selvagem, e é a segunda floresta mais ameaçada do mundo (WORLD WILDLIFE FUND - WWF, 2006); faz parte das 15 regiões identificadas mundialmente como hotspots (áreas com alta biodiversidade, altas taxas de endemismo e, ao mesmo tempo, com alta pressão antrópica) (CONSELHO NACIONAL DE PESQUISA - CNPq, 2001). Foi o ecossistema brasileiro que mais sofreu com os impactos ambientais dos ciclos econômicos da história do país (CONSELHO NACIONAL DE PESQUISA CNPq, 2001; WORLD WILDLIFE FUND - WWF, 2006). É um ecossistema rico em biodiversidade que ocorre em áreas que podem assumir um isolamento devido às condições geo-climatológicas. Este isolamento propicia à evolução natural das espécies a possibilidade de endemismo, o que torna a Floresta Atlântica ainda mais importante por apresentar regiões com espéci- 
es não existentes em qualquer outro lugar do globo.

A história mostra que, desde a colonização européia, a Floresta Atlântica tem enfrentado impactos ambientais ocasionados pela ação do ser humano (pressão antrópica), como por exemplo, a ocupação maciça e desordenada do solo, o extrativismo de espécies pertencentes à dinâmica da floresta com objetivo comercial, o meio de produção (por exemplo, a instalação de parques industriais e vilas de empregados), a inserção de novas tecnologias e o desconhecimento da importância de uma atitude correta em relação à questão da razão social.

As pressões antrópicas que ocorrem mais recentemente manifestam-se tanto no ambiente natural quanto no ambiente cultural das comunidades localizadas em áreas com relevância ambiental da Floresta Atlântica. $\mathrm{O}$ aumento dos processos ligados à incorporação das terras aos modos de produção vigentes, iniciados sempre pela etapa do desmatamento, consiste um importante impacto ambiental. A deterioração das condições de vida no ambiente rural e urbano e a perda de traços culturais autóctones também são impactos decorrentes na Floresta Atlântica. A associação dessas pressões sugere uma condição comercial lucrativa de exploração extensiva dos recursos naturais, uma vez que a Floresta Atlântica foi base de produção empresarial e conectava-se no início da seqüência logística, como matéria-prima (CONSELHO NACIONAL DE PESQUISA - CNPq, 2001).

A pressão exercida pelas comunidades tradicionais no ecossistema é insignificante se comparada com a pressão exercida pelas grandes empresas.

Resultado dos diferentes ciclos de exploração econômica, a destruição da Floresta Atlântica ocorreu desde o início da colonização européia até a alta densidade demográfica em sua área atual de abrangência, decorrente do uso de áreas para a criação de espaços urbanos (MINISTÉRIO DO MEIO AMBIENTE MMA, 2000).

\section{4. ÁREA DE PROTEÇÃO AMBIENTAL DE GUARATUBA - PR}

AAPAé uma região com qualidades ambientais relevantes à conservação e apresenta certa ocupação humana, pelo fato que o domínio da terra pode ser público ou privado. Existe uma série de restrições quanto ao uso do solo e dos recursos naturais com o objetivo de disciplinar o extrativismo por parte das populações existentes. No geral, estas áreas têm atributos bióticos e abióticos, estéticos ou culturais importantes para a qualidade de vida.

AAPA de Guaratuba (FIG. 01), foi criada pelo Decreto Estadual n 1.234 de 27 de Março de 1992. É composta por porções dos municípios de Matinhos, Paranaguá, São José dos Pinhais, Tijucas do Sul e grande parte do município de Guaratuba. Inserida na Floresta Atlântica, incide sobre ela o Decreto Federal $\mathrm{n}^{\circ} 750$ de 10 de fevereiro de 1993 que dispõe sobre o corte, a exploração e a supressão de vegetação primária ou nos estágios avançado e médio de regeneração (INSTITUTO AMBIENTAL DO PARANÁ - IAP, 2006). Também estão inseridas no perímetro da APA de Guaratuba, o Parque Estadual do Boguaçu, com 6.052 ha, o Parque Nacional Saint Hilaire/Lange, com 25.161 ha e a Lagoa do Parado, de utilidade pública.

O perímetro da APA abrange parte do Primeiro Planalto, a Serra do Mar, e grande parte da Planície Litorânea, que inclui a Baía de Guaratuba. Abriga vários rios e riachos, entre os mais importantes estão os rios Sagrado, Cubatãozinho, Canavieiras, Arraial e São João (formadores do rio Cubatão), São Joãozinho (paralelo à BR-376). Há duas grandes represas: Vossoroca e Guaricana, ambas da Companhia Paranaense de Energia Elétrica (COPEL). Os principais grupos geomorfológicos serranos são as Serras das Canavieiras, da Igreja, dos Castelhanos, Guaraparim, Araraquara, Imbira e do Papanduva. Assim, em conjunto com as APA's de Guaraqueçaba e da Serra do Mar, a APA de Guaratuba conclui a mais completa Unidade de Conservação do bioma Floresta Ombrófila Densa (Floresta Atlântica) dentro de um Estado (INSTITUTO AMBIENTAL DO PARANÁ - IAP, 2006). O clima é considerado úmido e com alta pluviosidade. 
Impactos ambientais na Área de Proteção Ambiental (APA) de Guaratuba, Paraná, Brasil, sob o ponto de vista de moradores tradicionais Raphael Telles Kantek, Klaus Dieter Sautter, Mário Sérgio Michaliszyn

\section{COMUNIDADES TRADICIONAIS NAAPA DE GUARATUBA: O QUE DIZEM E PENSAM OS CAIÇARAS}

Definem-se "populações tradicionais" como grupos assentados em territórios delimitados ou delimitáveis, que exploram recursos comuns, sempre politicamente subordinados, com identidade cultural forte e diferente daquela nacional. Devido à relação cotidiana direta com o meio que exploram, desenvolveram um complexo conhecimento sobre os recursos e sua conservação (DIEGUES, 1992; COLCHESTER, 2000).

Os recursos naturais formam a base da cultura material dessas populações, que têm em seu modo de vida uma relação intrínseca com o meio ambiente. Diferentes pesquisadores tratam sobre o uso destes recursos, organizando, citando e enumerando-os de acordo com a finalidade definida por essas populações: alimentação, cura de doenças, ornamentos, rituais, indumentária, utensílios domésticos, para caça e pesca, venenos e outros (CARVALHO, 2001).

As comunidades são formadas por famílias que apresentam maiores ou menores capacidades de articulação com a sociedade envolvente. Uma vez que, comunidades, costumes e técnicas fundamentam e são derivados de domínios territoriais específicos, a essas populações se associam direitos comuns sobre terra e recursos: uso partilhado, áreas coletivas usufruídas por grupos de vizinhança ou parentesco, partilhas de uso dentro de uma mesma unidade de domínio, gradações de domínio e uso da terra. Os usos são mediados por relações de parentesco ou proximidade e norteados pela necessidade de regulação, pois são essenciais à reprodução do grupo (MARTINS, 1981; BARBOSA, 1986; DIEGUES, 1995; WOORTMANN, 1997; GALIZONI, 2000).

Neste trabalho constatou-se a existência de seis comunidades tradicionais instaladas dentro da APA de Guaratuba (FIG. 01). A Comunidade Castelhanos está localizada no município de São José dos Pinhais e tem no cultivo da banana sua principal fonte de renda. A Comunidade Pedra Branca do Araraquara está localizada no município de Guaratuba. Tem sua economia voltada para monocultura da banana e o comércio lindeiro na BR 376. Também localizada no município de Guaratuba, a Comunidade Cubatão explora a monocultura da banana e, recentemente, a monocultura do palmito de palmeira real e de pupunha. A Comunidade Limeira pertence ao município de Guaratuba e abrange as localidades da Limeira, Rasgado e Rasgadinho. Sua economia segue o mesmo exemplo das demais comunidades. Porém, Limeira se destaca pela criação de gado, dentre outras práticas rurais, além do cultivo da banana ou de palmito pupunha. As Comunidades Cabaraquara e do Parati, no município de Guaratuba, desenvolvem práticas extrativistas - pesca e manguezais. Existem alguns projetos de desenvolvimento sustentável, envolvendo as comunidades tradicionais, projetos de criação em confinamento de espécies marinhas nativas (Ex: cultivo de ostra e camarão). A região possui uma população flutuante que injeta dinheiro na economia local. Segundo relato dos moradores, com a criação do Parque Nacional Saint Hilaire/ Langue, as práticas do ecoturismo tornaram-se restritas e são dificultadas pelo governo. Todos os entrevistados apresentam características típicas de populações tradicionais. Juntamente com toda a bagagem cultural herdada de seus ancestrais, as práticas extrativistas de subsistência desenvolvidas na APA de Guaratuba (a extração de subsistência do palmito, a caça e a pesca) estão fortemente presentes na história e na identidade destes grupos. Dentre as falas e relatos colhidos em entrevistas, comentam os moradores:

"A APA de Guaratuba é a minha vida, é o lugar onde sou pessoa digna porque não preciso de nada, a natureza nos dá tudo, felizmente ainda dá tudo por meio de seus recursos naturais. (...) O problema é que tem gente que tem que parar, que faz a extração sem nem precisar, às vezes desperdiça só por matar. Eu acredito que está certo algum recurso natural se utilizar, já que nesse local a minha família veio morar, porque de nada adianta eu aqui morar, se tudo na loja eu ir comprar. O palmito tem por todos os lugares aqui, eu já cortei uma vez quando andava percorrendo alguma trilha na Floresta Atlântica, cortei o palmito porque estava com fome na oca- 
sião. (...) Aqui já tem pouco, mas ainda é fácil de achar, basta procurar. O que também é muito procurada é a nossa fauna e a nossa flora que são exuberantes para os nossos olhos, mas principalmente aos olhos de quem vem de fora."

Segundo Agripa (2002), as populações tradicionais destacam-se pela noção de território, por onde uma porção da natureza é reivindicada para todos, ou para parte de seus membros, instituindo direitos estáveis de acesso, controle e uso sobre a totalidade ou ainda para parte dos recursos naturais. Nesta pesquisa, os entrevistados revelam a aceitação da natureza como fonte de alimento e a tendência natural das populações tradicionais, de regular o desperdício, vedando ou limitando os usos predatórios, mercantis ou extensivos. Comentam os entrevistados sobre o acesso aos recursos naturais que as espécies são por eles utilizadas “(...) em momentos difíceis, ou então quando vier fácil na porta de casa, porque meu pai me ensinou que a natureza está nos dando, para nos alimentar. Esta é a natureza das pessoas, comer animais e plantas (...) não vou morrer de fome, sendo que a natureza me provê muitas variedades deliciosas.

As populações conseguem não só conservar, mas também ampliar a qualidade dos recursos, a biodiversidade ou coibir o consumo abusivo de outros grupos ou interesses mercantis. Para Smeke et al. (2003), o posicionamento antiprogresso (contra a "urbanização da vila"), que, em geral, as populações tradicionais demonstram, ao contrário do que muitas pessoas pensam, não significa que estão parados no tempo, e sim protegendo algo importante: cultura e natureza.

De acordo com estes moradores tradicionais, o palmito-jussara, é fonte de alimento. A construção do conhecimento das técnicas costumeiras de extração do palmito e outros, exerceu no passado, uma forte construção conceitual, para a geração anterior que vivia na APA, se comparada com a atual, sobretudo durante o período em que as fábricas de extração do palmito ali estiveram. Embora hoje o palmito tenha recursos legais de proteção, sua extração ainda se faz presente na cultura e no imaginário social daquela po- pulação e de muitas outras pessoas envolvidas com sua comercialização.

Para Diegues (2000a), no entendimento de tradição em movimento, o que importa marcar é "que algo é entregue" de geração a geração para reproduzirse no tempo, ainda que ressignificado no fluxo da história. Esta ressignificação pode ser observada em diferentes falas dos entrevistados. “(...) Eu gostaria que meu filho pudesse aprender, tudo o que aprendi, com esta natureza que está ai. E pra que isto ocorra, ele tem que querer, e a natureza tem que existir, pelo menos do que é hoje pra melhor, é isso que desejo.

A pesquisa também procurou identificar o envolvimento da população com o meio ambiente, seu conhecimento sobre o ecossistema e a forma como se utilizam dos recursos naturais. Observou-se que os entrevistados detêm conhecimento especializado sobre a sua região, o ecossistema e possuem consciência conservacionista. Embora conscientizados das reduções dos espaços naturais de extrativismo, e da conseqüente diminuição de oferta natural destes recursos ainda assim vêem a si e aos demais membros da comunidade como envolvidos em práticas de consumo que aprenderam diretamente no cotidiano de relações com o ecossistema.

"Esse meu conhecimento sobre as belezas naturais e culturais da região, faz despertar em mim um sentimento de propriedade e zelo. Muitas vezes demonstro conhecer muito mais sobre a região, do que eu próprio imaginava. Como se colocado à prova, e em condições extremas, todas as informações ancestrais apresentadas em meu sangue e ao meu cotidiano fossem muito mais evidentes à de um forasteiro. (...)"

O ponto de vista dos entrevistados encontra semelhança em Diegues (2000a), ao afirmar que as populações tradicionais conhecem e vivem seu território, e ao mesmo tempo desenvolvem condições para normalizá-lo. Para estes grupos, o conhecimento está associado à posse da terra no momento de produzir e de gerir as circunstâncias específicas de cada localida- 
Impactos ambientais na Área de Proteção Ambiental (APA) de Guaratuba, Paraná, Brasil, sob o ponto de vista de moradores tradicionais Raphael Telles Kantek, Klaus Dieter Sautter, Mário Sérgio Michaliszyn

de tradicional. E é por meio do conhecimento que demonstram o domínio do território específico, e explicam que produzir é a base do conservar. A este respeito, dizem os entrevistados: "A maneira que entendo o meio ambiente é a forma que me relaciono com a natureza, e com as pessoas que me ensinaram como reagir às intempéries. Esta condição natural de vida em um habitat sem as facilidades das cidades é o que determinou o grau de conhecimento que eu tenho sobre a região..."

Brandão (1981), Posey (1987), Turner (1990) e Romeiro (1998), afirmam que as populações tradicionais realizam com a natureza uma cadeia de negociações. Com esta série de negociações, estipulam as regras do extrativismo. Sendo assim, as técnicas agrícolas variam não somente na história, mas também no decorrer da variação dos ambientes em resposta às atividades exercidas. Populações, natureza e técnicas formam, em muitas situações, um equilíbrio ecológico de relações. Este equilíbrio, envolvendo diversas situações, não pode perder nenhum elemento, porque o balanço final da perda de algum elemento, provoca o desequilíbrio no ecossistema. Característica esta que pode ser interpretada como aumento da pressão antrópica exercida pelas comunidades tradicionais. Comentam os moradores que "Antigamente a natureza era infinita, e hoje aqui na nossa região já se percebe ela finita. A falta de manejo apropriado em anos anteriores já reflete a devastação causada pelo homem, na natureza aqui da APA".

As populações tradicionais da APA de Guaratuba apresentam carência de informações administrativas e científicas sobre o meio ambiente, ao manifestar o seu parecer sobre as necessidades da região. Esta atitude provém de uma consciência construída pelas populações tradicionais, após uma capacitação (aulas de educação ambiental, por exemplo). Para Fortes e Rammê (s/data), a carência social, manifestada na falta de conhecimento sobre as coerências científicas e legais que envolvem a esfera de seu habitat, torna-se a ferramenta hábil para se identificar a fragilidade do sistema de defesa e proteção do meio ambiente. Comentam os entrevistados: “...Eu sou meio leigo nesses assuntos de ciência, mas conheço também muitas espécies de plantas e animais (...) Esse conhecimento adquirido de maneira simples e humilde, que me faz perceber que temos que cuidar aqui da região..."

Como generalidade tocante, as populações tradicionais apresentam-se em diversas situações de conflito, relacionadas principalmente com a invasão de suas terras pela especulação imobiliária (KEMPF, 1993; DIEGUES, 1995; 2000a; DIEGUES; ARRUDA, 2001; AGRIPA, 2002). Para um dos moradores, “....A falta de manejo apropriado em anos anteriores já reflete a devastação causada pelo homem, na natureza aqui da APA de Guaratuba..."

Para Albagli (2003a), desde os tempos remotos, as populações tradicionais vêm contribuindo para a conservação e o desenvolvimento sustentável in situ de diversas espécies florestais importantes, utilizando o conhecimento empiricamente acumulado sobre os habitats naturais, bem como de suas práticas agrícolas sustentáveis e de extrativismo de subsistência adequadas ao meio ambiente local, e atuando como verdadeiros guardiões do patrimônio biogenético ambiental.

Procurou-se identificar entre os entrevistados a sua vontade de participar de atividades que promovam o envolvimento da comunidade, que apresentem conhecimento sobre as ações governamentais, a ecologia da região e a preocupação e vontade de melhorar as condições ambientais. Das entrevistas realizadas observou-se que existe vontade de aprender mais sobre a região e tudo que a envolve, tais como, saneamento, ecologia, conceitos de biodiversidade, ecossistemas, reciclagem de materiais e geopolítica. $\mathrm{O}$ conhecimento é visto como esperança de futuro, como possibilidade de melhoria das condições ambientais e da dignidade humana.

Segundo Diegues (2000b), as populações tradicionais tendem a proteger e gerenciar os recursos naturais tidos como comuns, contrapondo-se a grupos externos extrativistas, e construindo elaboradas regras para acesso e uso. Considerando o recurso um bem em comum, é necessário que sejam estipuladas regras pela maioria para o uso comum. As reuniões entre os 
integrantes da sociedade tradicional, não escrevem as conclusões; elas são ditas e repetidas durante gerações, e realmente estabelecem normas de uso comum. Vale a pena rever a fala do entrevistado, quando afirma que, "Como morador aqui da região da APA de Guaratuba, me sinto envolvido e responsável pelo ambiente coletivo ao qual pertenço..."

Na diferença entre a ausência de normas escritas e a presença de normas costumeiras, podem ser desconsideradas práticas que, às vezes, explicam ações coletivas e esforços comunitários que animam lutas locais e contribuem para conservação da biodiversidade (Diegues, 2000a).

Aqui, o discurso se caracteriza como a manifestação da carência, em ferramentas hábeis, para regular as individualidades capitalistas, que consome grandes áreas naturais. Para os entrevistados, o ambiente natural "é fonte de informação, e atua de maneira dinâmica para nós que moramos aqui e nos conhecemos. Estamos vivendo isso, mas infelizmente, sem saber exatamente o que está acontecendo. Se isso fosse feito aqui comigo e minha comunidade, com certeza em um breve futuro haveria grandes melhorias ambientais". Esta fala reflete a necessidade de, como afirma Albagli (2003b), prover meios legais, para que as populações tradicionais exerçam o direito de praticar e utilizar ferramentas destinadas a proteger os remanescentes que ainda estão disponíveis de maneira que a comunidade, segundo orientação científica especializada na área, apresente um parecer em conjunto. A este respeito, comentam os entrevistados que "...todo o conhecimento em prol da natureza é bem vindo, mas de maneira sutil, segundo o rendimento das pessoas e com alguma maneira de envolver todos os integrantes da comunidade. Assim posso cuidar melhor, dentro da lei, no que cabe à proteção da natureza..."

Para Batistella et al. (2005) o conhecimento tradicional assegura o acesso rápido a informações elementares para pesquisas científicas, além de dar subsídios à população local na defesa de "seu lugar". "...Aqui onde vivo o nivel de conhecimento das ciências naturais é muito baixo, o que nós sabemos é na prática, mas sem saber os porquês da ciência..."
Em um mundo cada vez mais globalizado e homogêneo, é crescente a idéia, de que a continuidade, da diversidade de culturas humanas é elemento fundamental. A constituição de sociedades pluralistas e democráticas, atrelando-se a isso a imutabilidade dos padrões culturais em que se deveriam manter as populações tradicionais nas unidades de conservação (Diegues; Arruda, 2001).

“...Eu acredito que mudando para melhor as condições de vida das pessoas, com a mudança que vai nos ensinar a cuidar melhor da natureza e nos ensinar os porquês da ciência natural, vou recuperar a dignidade que meus ancestrais tinham, e o sentimento de grandeza que a natureza intocada transmitia, e que talvez não transmita aos meus filhos e netos..."

Diegues e Arruda (2001) relatam que o campo de aplicação das técnicas das populações tradicionais geralmente é restrito à área de exploração em comum das comunidades e aos objetivos extrativistas previamente planejados, a possibilidade de generalização é limitada porque busca conhecer uma área específica e um conjunto de variáveis que agem sobre ela, apresentando-se de certa forma como endemismo cultural. Para estes endemismos as soluções não podem ser generalizadas, cada lugar é uma forma específica de reação natural ao manejo humano. É por isso que o envolvimento da sociedade tradicional é necessário, justificando novamente a preocupação da comunidade, que sem saber o porquê, ou o que é, mas sabe que está acontecendo e se vê presente no envolvimento da sua região, como afirmou o entrevistado: “....Eu devo começar a cuidar de onde moro; quem vai cuidar pra mim, vocês de fora? Tudo o que posso aprender sobre a natureza, é de bom agrado, mas muitas vezes o que passa na televisão não é o suficiente..."

Segundo Ribeiro (1987), os contínuos insucessos e limitações de políticas públicas de gestão dos recursos naturais refletem sobre os sistemas locais de gestão. Os costumes específicos de grupos rurais conseguem, muitas vezes, ser muito mais eficientes que o 
Impactos ambientais na Área de Proteção Ambiental (APA) de Guaratuba, Paraná, Brasil, sob o ponto de vista de moradores tradicionais Raphael Telles Kantek, Klaus Dieter Sautter, Mário Sérgio Michaliszyn

setor público, que a iniciativa privada, e que os sistemas de gestão social compartilhada, no que diz respeito à conservação das áreas naturais.

“(...) Eu gostaria mesmo que houvesse algum curso que envolva a comunidade com algo que possa melhorar tanto a condição do natural quanto do social. Aqui na APA nós moramos junto com o ambiente natural, e não podemos ser tratadas separadamente, ou com menos importância."

Na seqüência das entrevistas com moradores, procurou-se identificar a compreensão destes acerca do futuro, sua percepção sobre as condições naturais decorrentes de hábitos extrativistas e da relação em que o homem torna-se um elemento insustentável em contraponto à natureza, e não mais parte integrante dela.

Pode-se observar que existe a consciência conservacionista de indignação pelo considerado bem em comum, por integrantes externos às comunidades residentes nas áreas naturais, que são as florestas dentro da APA de Guaratuba. Os entrevistados demonstram compreender a necessidade de conscientização, implementação de novos métodos de convivência com a floresta, transformando a relação sustentável com alterações no cotidiano elegidas pelo conhecimento da comunidade e provendo a melhoria ambiental e cultural.

$\mathrm{Na}$ fala dos entrevistados, observa-se a relação estreita que estes mantêm com o ambiente.

"Eu moro aqui e conheço muito mais do que ninguém essa área aqui de onde eu moro. Por essas áreas aí, sei que entram pessoas com o objetivo de caçar, às vezes quando não estou cuidando, também caçam aqui onde eu cuido. Aqui na APA de Guaratuba, existem várias áreas, que é muito comum que, como os nossos ancestrais diziam: - "Eles derrubam só pra ver o tombo". Infelizmente, para nós que gostamos e cuidamos. Antigamente, se era preciso fazer uma casa ou uma canoa, se extraía madeira em abundância. Antigamente, eu entrava, com a matilha, e a espingarda
22 de tiro longo, na Floresta Atlântica, exercer meu papel de predador supremo da APA de Guaratuba. Eu entrava no período da manhã, na Floresta Atlântica, para trazer alguma mistura para o almoço. Os recursos eram de extrema abundância. Com o decorrer de algumas décadas, o incremento tecnológico tornou o ser humano muito mais perigoso para a Floresta Atlântica, que meros assassinos exóticos, em associação com outra espécie, no caso meus dois cachorrinho-magro-deandá-no-mato, com os sentidos aguçados capazes de localizar e encurralar diversas espécies nativas, liderados por um predador supremo, no caso a minha pessoa, e que disparo de espingarda projéteis de chumbo em alta velocidade, e com precisão de pontaria. (...)"

Para Fortes e Rammê (s/data), em cenários como este, prevalecem os interesses privados majoritários, com ponto de vista econômico ascendente. A ação corrupta e sem consciência ambiental, encontra a liberdade necessária para expandir o modelo de desenvolvimento econômico que se instalou a partir da revolução industrial. A mão-de-obra e o ambiente natural são meros elementos inseridos na cadeia econômica produtiva. Segundo Ribeiro (1987), a expansão tecnológica na agricultura agravou ainda mais a marginalização. As novas tecnologias concentraram-se em parâmetros como escala produtiva, custos e logística. Isto conduz, evidentemente, a procedimentos técnicos profundamente homogeneizados que podem ser aplicados a qualquer espaço, produto, produtor ou ambiente; totalmente o oposto da lógica de vida campesina. Neste sentido, comenta o entrevistado:

"Hoje eu quero exercer o papel de controlador e regulador dos recursos naturais, porém me faltam educação e os meios por onde exercer a função. Estou de prontidão e de pronta ação. Porque acredito, dentro daquilo que aprendi por aqui mesmo, com meus pais e avós, segundo o conhecimento tradicional ancestral deles, e segundo também aquilo que eu apren$d i$, na minha vida com a natureza aqui da APA de Guaratuba, que em pouco tempo mui- 
tas espécies vão desaparecer, outras já estão desaparecendo aqui na APA de Guaratuba, se nada for feito."

Segundo Fortes e Rammê (s/data), a lógica campesina tende a ser ao mesmo tempo mais holística e mais localizada, mais diversificada e mais ambientalizada. Portanto, situou-se na contracorrente da lógica da transformação tecnológica, da integração produtiva agroindustrial e mercantil ocupando, cada vez mais, uma posição de marginalidade e empobrecimento. Observe-se o discurso a seguir:

\section{“...O incremento do maquinário tecnológico} tornou a presença humana, na Floresta Atlântica em uma força sobre-humana fazedora de campo. O campo por aqui na APA de Guaratuba, nós entendemos, como aquela área descampada, onde o trator passou por cima, e fez o campo. E é contra essa força burocrática fazedora de campo em especial que quero brigar, porque ela vem aqui faz o campo, planta em cima ou deixa como campo mesmo, e tira a nossa Floresta Atlântica, eu sei que é muito bonito e lucrativo o campo pra eles, que são de opinião contrária, mas eu prefiro a natureza como ela é..."

Segundo Diegues (1995) os territórios são marcados por fronteiras definidas, normas coletivas de formulação de regulamentos internos, controle comunitário dos recursos naturais, sanções específicas aplicáveis ao descumprimento destes regulamentos, e mecanismos internos de negociação dos conflitos. Estas características geralmente presentes nas comunidades tradicionais, tornam possível controlar a logística dos recursos naturais, delimitá-los para o consumo comunitário e preservar grandes áreas para usufruto coletivo. O desenvolvimento deve ser um processo tão externo que interfere quase que somente as circunvizinhanças legais e morais das sociedades tradicionais da APA de Guaratuba, e será tão excludente para elas como se fosse um desenvolvimento pensado para outros povos, lugares e territórios.

Em associação aos ecossistemas da APA de
Guaratuba, encontram-se comunidades residentes em locais isolados devido a condições climáticas e geográficas. Cada um destes agrupamentos estabelece características e relações muito particulares com o meio ambiente.

Descritos como obstáculos à modernização $\mathrm{e}$ ao desenvolvimento econômico, especialmente quando interesses poderosos concorrem pelo acesso e pelo uso dos recursos naturais, esquecem os defensores deste tipo de pensamento, que os povos indígenas e outras populações tradicionais, há muito desenvolveram sistemas elaborados de conhecimento (base de suas estratégias de subsistência) sobre a ecologia, e os usos práticos dos recursos da flora e fauna.

Observa-se pelas entrevistas que uma das maneiras mais eficazes, dignas e com responsabilidade sócio-ambiental que garantiria o monitoramento e controle da degradação das áreas naturais poderia ser a de atribuir este encargo à população local, por meio de trabalho remunerado.

Tomou-se como mais uma idéia central a ser pesquisada, a referência dos grupos entrevistados pelos recursos industrializados em detrimento às práticas tradicionais e o grau de insatisfação destes para com o Governo. Pode-se observar que em termos culturais, as populações tradicionais, que ainda reconstroem seu cotidiano baseadas na estrutura extrativista tradicional de subsistência, estão sujeitas a este processo devido ao alto grau de exclusão social. Muitas destas pessoas parecem demonstrar pouco ou quase nenhum apreço aos conhecimentos de seus ancestrais, mas ainda assim obrigam-se a utilizá-los.

"Na floresta, os recursos ainda estão disponíveis, e são maravilhosos, porém é muito dificil o translado na floresta. Eu gostaria que o Governo me ajudasse, e aos integrantes aqui da comunidade onde vivo, oferecendo meios para que nós, aqui da APA de Guaratuba pudéssemos desfrutar de certas facilidades dos meios industrializados. Com certeza, muitos de nós, já não realizariam o extrativismo, aceitando a troca pelos recursos industrializados." 
$\mathrm{O}$ discurso colhido entre moradores tradicionais evidencia que estes, assim como outros grupos que compõem sociedades de campesinato, marginalizados pela moderna sociedade atual demonstram disposição e interesse a mudanças em favor de seu habitat, sobretudo quando tais mudanças são propostas pela sociedade externa. Segundo Ribeiro (1987), é a visão holística contra a corrente da modernização, que tenta se opor ao inevitável final marginalizado e empobrecido do sistema estabelecido atualmente. Vencidos, entregam-se à sociedade de consumo. Diz o entrevistado: "Eu vivo aqui e gosto de viver aqui, e isto é certo. Mas também gosto de consumir produtos originados das cidades, consumir as facilidades dos grandes centros urbanos, sem ter que ficar sofrendo dentro da Floresta Atlântica..."

Segundo Diegues (2000a, b), o saber tradicional só começou a ser valorizado no decorrer das últimas décadas e, principalmente, a partir dos anos 80, se tornou ainda mais relevante para intervir na crise ecológica. É importante conhecer práticas e representações de diferentes grupos tradicionais, pois estes conseguiram executar diferentes planos de manejo sobre os ecossistemas ao longo do tempo. Além de compartilhar sabedoria popular com conhecimento científico do meio natural, a diversidade cultural em si é valorizada ao se estudar os processos tradicionais de desenvolvimento.

Diegues (2000a, b) considera que as políticas aplicadas para este processo de inserção social e econômica tiveram na verdade efeitos localizados, que jamais alteraram a posição de subordinação política, econômica e, sobretudo, cultural do campesinato na sociedade rural brasileira.

Ao referir-se sobre a relação com o poder público (o Estado e seus representantes), os entrevistados comentam:

"O Governo e os políticos poderiam e deveriam, exercer a voz do povo, aqui pela APA de Guaratuba também. Eles vêm e passam, sempre muito rápido, e a parte assistencial tanto com a natureza, quanto com a socieda- de, sempre fica pra depois. (...) Eu e minha família, minha comunidade, e também meus parentes que moram aqui na APA de Guaratuba, queremos participar, ser ouvidos e conhecer os projetos dos políticos e do Governo aqui para nossa região".

Ribeiro (1987) relata que as sociedades tradicionais foram, ao longo da história, marginalizadas e desqualificadas social e culturalmente. A expansão tecnológica na agricultura acentuou ainda mais a marginalização das sociedades tradicionais, que perdem espaço na mão de obra da lavoura para a automatização da colheita. As populações tradicionais contam com o apoio de iniciativas, por meio de projetos que expressam a preocupação do Governo Federal que as considera como parte importante do mosaico de soluções para a proteção ambiental e o desenvolvimento sustentável em regiões de florestas tropicais. Porém, no que diz respeito à APA de Guaratuba, até o presente momento, não há qualquer apoio de iniciativa federal.

“... Eu gostaria que houvesse alguma forma de comunicação facilitada, o pronto atendimento para os problemas com a natureza, $e$ para as carências das pessoas que assim como nós, aqui da minha comunidade, vivemos aqui na APA de Guaratuba..."

Sem o conhecimento de práticas sustentáveis, as áreas naturais, sujeitas a essa condição lucrativa, tendem a desaparecer muito rapidamente. Diversos estudos têm sugerido que as comunidades tradicionais estejam envolvidas na proteção e gestão das unidades de conservação, construindo um novo modelo de conservação e desenvolvimento comunitário.

\section{SISTEMA DE INFORMAÇÃO GEOGRÁFICA (SIG)}

A partir das informações do dado matricial do SIG, com referente confirmação em campo, obteve-se a descrição de 18 formas de pressão antrópica que impactam a APA de Guaratuba. São elas: Represa do Vossoroca, Rodovia BR 277, Circunvizinhança da cidade de Garuva, Cultivos de banana e arroz, Áreas de 


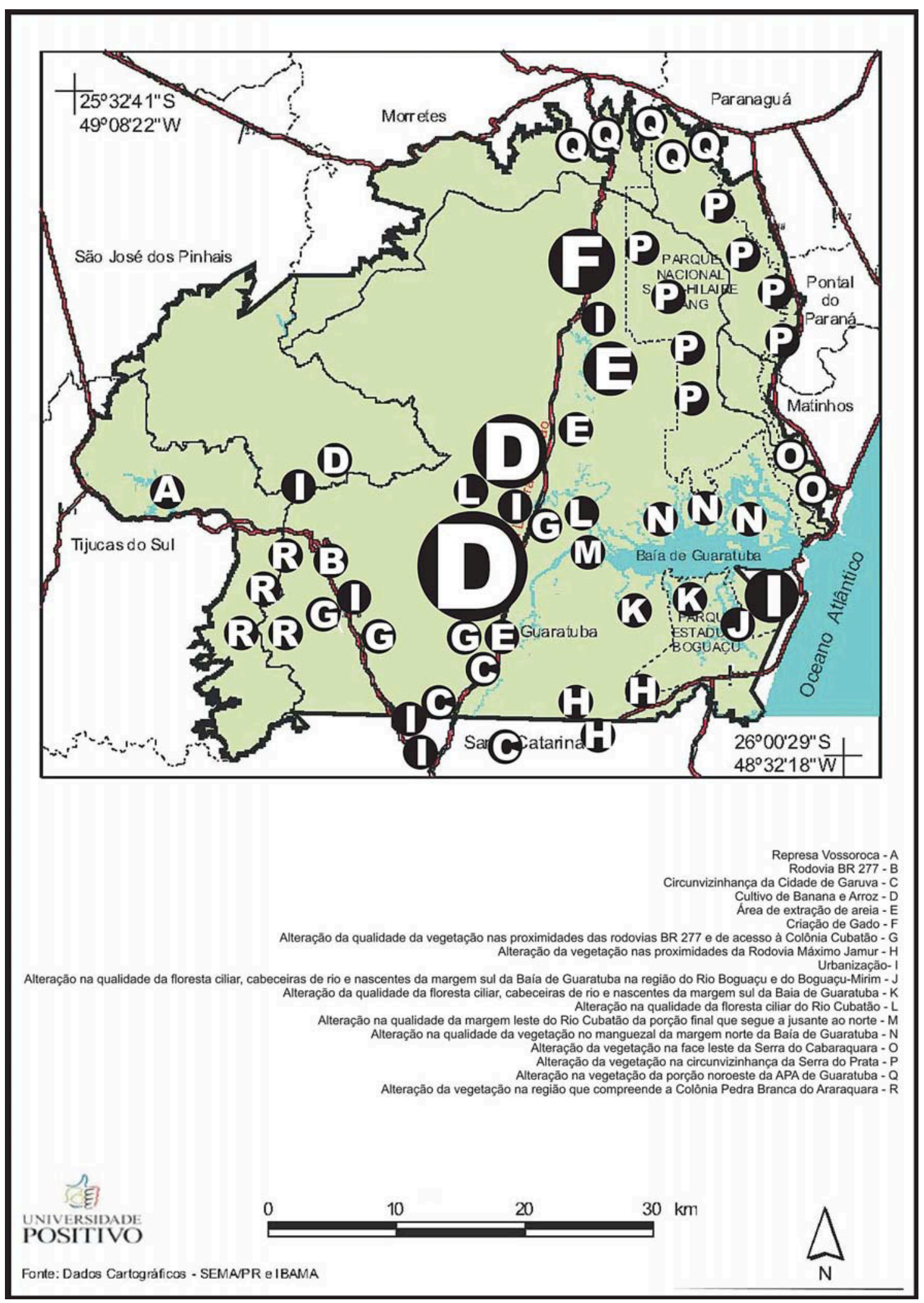

FIGURA 2. Impactos ambientais de origem antropogênica na APA de Guaratuba, PR. Mapa adaptado de SILVEIRA et al. (2005). 
extração de areia, Criação de gado, Alteração da qualidade da vegetação nas proximidades das rodovias BR 277 e de acesso à Colônia Cubatão, Alteração da vegetação nas proximidades da Rodovia Máximo Jamur, Urbanização, Alteração na qualidade da floresta ciliar, cabeceiras de rio e nascentes da margem sul da Baía de Guaratuba na região do Rio Boguaçu e do BoguaçuMirim, Alteração da qualidade da floresta ciliar, cabeceiras de rio e nascentes da margem sul da Baia de Guaratuba, Alteração na qualidade da floresta ciliar do Rio Cubatão, Alteração na qualidade da margem leste do Rio Cubatão da porção final que segue a jusante ao norte, Alteração na qualidade da vegetação no manguezal da margem norte da Baía de Guaratuba, Alteração da vegetação na face leste da Serra do Cabaraquara, Alteração da vegetação na circunvizinhança da Serra do Prata, Alteração na vegetação da porção noroeste da APA de Guaratuba e Alteração da vegetação na região que compreende a Colônia Pedra Branca do Araraquara (FIG. 2).

\section{INTERAÇÃO ENTRE DSC E SIG}

Segundo Burrough e Mcdonnel (1998), Maguire et al. (1999) e Gunasekera (2004), é natural, na área de SIG, a obtenção de dados, de maneira a gerar um maior número de métodos de interpretação, e integração de dados adicionais. A análise dos dados foi realizada de maneira comparativa com as situações evidenciadas durante a fase de campo, com dois objetivos que, em parceria, poderiam fornecer dados sobre a relação da população e do meio ambiente.

O SIG utiliza a interpretação sócio-cultural obtida em campo, das condições pertencentes à massa de dados da pesquisa DSC. Os dados provenientes do DSC devem ser analisados como um manual semiótico de interpretação cultural das relações antrópicas, para visualização de maneira holística dos objetos geográficos descritos.

Os dados provenientes do SIG apontam as condições ambientais segundo a descrição em proporções macro de dimensões e localizações geográficas. $\mathrm{E}$ os dados provenientes do DSC apontam as condições de relação antrópica na área, segundo a des- crição sócio-cultural.

O critério básico para a formação dos mapas finais foi a análise da Remoção Total da Cobertura Vegetal Original. As grandes áreas naturais removidas são pertencentes aos valores culturais das pessoas que dependem da biota para sobreviver. Todo o conhecimento, adquirido pelas práticas ancestrais, assim como as preocupações com relação à conservação, igualmente estão presentes entre os integrantes das comunidades tradicionais de Guaratuba, em decorrência da percepção da diminuição da qualidade das áreas naturais, e se encontram incluídas nas falas dos entrevistados.

As comunidades tradicionais reconhecem os prejuízos provocados pela remoção total da cobertura vegetal original em grandes áreas. Tais áreas são criadas com objetivo de obter desenvolvimento social e comercial rentável, tornando o ser humano um elemento comercial inserido na Floresta Atlântica que pode alcançar um potencial destrutivo muito além do alcance de regeneração da floresta. As comunidades tradicionais têm hábito extrativista. Por outro lado, também é perceptível sua preocupação com a preservação ambiental.

Os entrevistados demonstram um forte descontentamento em relação às áreas que antes eram floresta e agora são elementos de uma conexão lucrativa da logística agrícola. Essas áreas apresentam grande dispersão dentro da APA, segundo a informação da população tradicional, confirmada pelos dados SIG. A preocupação em diferentes comunidades tradicionais está refletida os dados SIG que apresentam grandes áreas com remoção total da cobertura vegetal original. A população tradicional, sem ter o conhecimento dos dados SIG, confirma o alarmante estado de degradação evidenciado pelas grandes quantidades de tons claros (os tons escuros representam maior densidade de vegetação, e os tons claros, menor densidade de vegetação) encontrados em todos os mapas.

Embora as informações provenientes do SIG e do DSC sejam de procedências diferentes, apresentam resultados coerentes. Isto confirma o elevado conhecimento que as comunidades tradicionais têm so- 
bre a região de domínio. Como exemplo, é possível citar o fato de que toda região da planície do Cubatão apresenta populações tradicionais, e estas exercem influência sobre as áreas montanas e fluviais localizadas em sua circunvizinhança.

Os mapas apresentam alteração da vegetação em região montana sob área de influência das comunidades extrativistas da APA de Guaratuba localizadas à circunvizinhança das Serras do Castelhanos, Araraquara, Pedra Branca do Araraquara, Guaraparim, Cubatão e Prata. Essas áreas de circunvizinhança das serras citadas apresentam habitantes com características de população tradicional, podendo ser evidenciadas nos diferentes trechos de entrevistas aqui apresentados.

As características extrativistas exercem diversas formas de pressão sobre a biota, como, por exemplo, a extração seletiva de espécies animais e vegetais, a ocupação do solo com moradia e lavoura tradicional, a formação de estradas e trilhas para percorrer o ambiente natural. A associação desses fatores contribui para uma coloração em tons claros apresentados nos dados SIG dos mapas. Estas colorações claras ocorrem em áreas que seguem a tendência natural de ocupação e utilização do terreno pelas comunidades tradicionais, situadas em áreas de relevo e acesso facilitado. Essas áreas são encontradas nos mapas com regiões de maior intensidade de impacto (tons mais claros), localizadas na base das serras estendendo-se até o cume das faces adjacentes às áreas de ocupação antrópica, como, por exemplo, as faces adjacentes da Serra da Pedra Branca do Araraquara e Serra do Araraquara, na rodovia $\mathrm{BR} 277$, e as faces adjacentes à rodovia de acesso à Colônia Cubatão, da Serra do Araraquara, Serra do Guaraparim e Serra do Cubatão. A Serra do Prata tem sua maior influência ocasionada pela facilidade de acesso e instalação de comércios lindeiros na rodovia Alexandra-Matinhos e PR 376.

Essas áreas apresentam um padrão de alteração da vegetação que começa com um ponto (podendo ser uma área bem delimitada ou apenas a linha estabelecendo a rodovia nos mapas) central de influência, onde ocorre a coloração mais clara para a re- gião, que vem a representar área urbanizada. Esses dados SIG estão também presentes na posição conservacionista do DSC.

Durante a fase de campo, foi evidenciado que o interior, que aqui compreende a região de área natural, dentro da APA de Guaratuba, afastada das rodovias, é de conhecimento único das populações tradicionais.

\section{CONCLUSÃO}

O processo de levantamento de dados ocorreu de maneira eficiente. O SIG da APA de Guaratuba permitiu a confecção de mapas com características matriciais de variação da vegetação, que são um registro ambiental da alarmante situação em que se encontra a vida selvagem (fauna e flora) na APA de Guaratuba.

Foram levantados 18 impactos ambientais; sendo o principal as rodovias existentes, porque é através delas que todos os demais processos impactantes são facilitados. Segundo os mapas de variação de vegetação, as áreas de maior influência impactante das comunidades estão as margens das rodovias.

A situação alarmante é relatada igualmente pelas populações tradicionais entrevistadas. Foram levantados, por meio das entrevistas, Discursos do Sujeito Coletivo (DSCs), que relatam a maneira campesina de relacionamento entre as comunidades tradicionais e o meio ambiente. A dualidade na procedência dos dados é o resultado associativo entre as metodologias. As áreas naturais estão diminuindo devido ao processo de crescimento populacional em que a atual civilização se encontra. Esse processo, em contrapartida à oferta de insumos e serviços, é decorrente de uma consciência capitalista lucrativa, que se espalha entre os projetos econômicos da população residente em uma área qualquer, que acabam sendo envolvidos com a condição comercial lucrativa da sociedade moderna atual.

Dentro do perímetro da APA de Guaratuba não é diferente. A consciência comercial lucrativa existe da mesma maneira que nas cidades, porém os meios de produção são os insumos oferecidos pela floresta. $\mathrm{O}$ 
escritório do caboclo é a floresta, e é por meio dele que tira seu sustento e de sua família. É na floresta que faz suas descobertas profissionais, supera-se e sente-se importante como ser humano e como profissional. O caboclo é o executivo da floresta, e deve ser valorizado como tal. É com o conhecimento tradicional do caboclo que será possível realizar novos planos de gestão e diretrizes para as Unidades de Conservação.

As populações tradicionais devem ser devidamente capacitadas, remuneradas e encarregadas em preservar a floresta da APA de Guaratuba. O caboclo deve preservar e ter os meios para executar a função remunerada de salvaguardo da floresta da APA de Guaratuba.

É imprescindível que se monitore de maneira eficiente, vindo a utilizar as populações tradicionais, como ferramenta, contra a ação impactante da remoção total da cobertura vegetal original, de regiões de florestas sob a ação de especulações imobiliária, agrícola e industrial. E ainda, que se monitore o interior da floresta, contra a ação de agressores de menor intensidade de impacto, como por exemplo, a extração seletiva de espécies pertencentes à dinâmica da floresta. A intensidade do impacto ambiental da extração seletiva de espécies pertencentes à dinâmica da floresta é menor, porém, no decorrer de um dado período essa ação contínua pode se tornar nociva.

\section{REFERÊNCIAS}

AGRIPA, A. F. Etnoconservação como política de meio ambiente no Brasil: desafios políticos de resistência e integração ao mundo globalizado. Agroecologia e desenvolvimento rural sustentável, v. 3, p.55-64, 2002.

ALBAGLI, S. Interesse global no saber local: a geopolítica da biodiversidade. In: SEMINÁRIO SABER LOCAL / INTERESSE GLOBAL: PROPRIEDADE INTELECTUAL, BIODIVERSIDADE E CONHECIMENTO TRADICIONAL NA AMAZÔNIA, 2003, Belém. Anais... Belém: CESUPA-MPEG, 2003a.

ALBAGLI, S. Informação, territorialização e inteligência local. In: ENCONTRO NACIONAL DE PESQUI-
SA EM CIÊNCIA DA IINFORMAÇÃO, 5., 2003, Belo Horizonte. Anais... Belo Horizonte: ECI/UFMG, 2003b.

BARBOSA, M. W. Redescobrindo a família rural. Revista Brasileira de Ciências Sociais, v. 1, n.1, p.6683, 1986.

BATISTELlA A. M., CASTRO C. P., VAD. J. D. Conhecimento dos moradores da comunidade de Boas Novas, no Lago Janauacá - Amazonas, sobre os hábitos alimentares dos peixes da região. Acta Amazônica, v. 35, p. $51-54,2005$.

BRANDÃO, C. R. Plantar, colher, comer. Rio de Janeiro: Ed. Graal, 1981.

BURROUGH, P. A.; MCDONNELL, R. A. Principles of geographical information systems. Spatial information systems and geostatistics. New York: Oxford University Press, 1998.

CARVALHO, H. Artesanato de caixeta em São Sebastião. 2001. 62 f. Dissertação (Mestrado em Recursos Florestais) Universidade de São Paulo/Escola Superior de Agricultura Luiz de Queiroz - USP/ESALQ, Piracicaba, 2001

CONSELHO NACIONAL DE PESQUISA - CNPq. Ciência e tecnologia para a Mata Atlântica: um programa de cooperação Brasil-Alemanha. Brasília: Ed. CNPq, 2001

COLCHESTER, M. Resgatando a natureza: comunidades tradicionais e áreas protegidas. In: DIEGUES, A.C. (org.) Etnoconservação: novos rumos para a proteção da natureza nos trópicos. São Paulo: Hucitec, 2000. p. $225-256$

DIEGUES, A. C. S. Os pescadores artesanais e a questão ambiental. Propostas Alternativas, v.53, p.31 35,1992 .

DIEGUES, A.C.S. Povos e mares: leituras em sócioantropologia marítima. São Paulo: NUPAUB/USP, 1995. 
DIEGUES, A.C.S. Etnoconservação da Natureza: enfoques alternativos. In: DIEGUES, A.C.S. (org.) Etnoconservação: novos rumos para a proteção da natureza nos trópicos. São Paulo: Hucitec, p. 1 - 46, 2000a.

DIEGUES, A.C.S. O mito moderno da natureza intocada. 3 ed. São Paulo: Hucitec, 2000b.

DIEGUES, A.C.; ARRUDA, R.S.V. (Org.) Saberes tradicionais e biodiversidade no Brasil. Brasília: MMA; São Paulo: USP, 2001.

FORTES, R.; RAMMÊ, R. Preservação da mata atlântica: o legítimo interesse público que deve prevalecer no caso da hidrelétrica de Barra Grande. s/data. Disponível em <http://www.natbrasil.org.br/docs/ artigo barra grande - rog_rio e reanata.pdf $>$. Acesso em fev.2009.

GALIZONI, F.M. A terra construida - Família, trabalho, ambiente e migrações no alto Jequitinhonha, MG. 2000. 92 f. Dissertação (Mestrado em Antropologia Social). Universidade de São Paulo - USP, São Paulo, 2000.

GUNASEKERA, R. Use of GIS for environmental impact assessment: an interdisciplinary approach. Interdisciplinary Science Reviews, v. 29, n. 1, p. 37 47, 2004.

INSTITUTO AMBIENTAL DO PARANÁ - IAP. Disponível em $<$ http://www.pr.gov.br/iap $>$. Acesso em jan. 2006.

KEMPF, E. In search of a home: protected living in or near protected areas. In: KEMPF, E. (Org) The law of the mother: protecting indigenous people in protected areas. San Francisco: Sierra Club Book, 1993. p.3 - 11.

LEFÈVRE F.; LEFÉVRE. A.M.C. O discurso do sujeito coletivo: um novo enfoque em pesquisa qualitative. Caxias do Sul: EDUCS, 2003.

MAGUIRE, D.J. et al. Geographical information systems management issues and applications. New
York: John Wiley \& Sons, 2 ed., 1999.

MARTINS, J.S. Os camponeses e a politica no Brasil. Petrópolis: Vozes, 1981.

MINISTÉRIO DO MEIO AMBIENTE - MMA. Avaliação e ações prioritárias para conservação da biodiversidade da Mata Atlântica e Campos Sulinos. Brasília: MMA/SBF, 2000.

MLYNARZ, R.B. Cultura tradicional e desenvolvimento: a dádiva como instrumental de análise para problema da cultura tradicional. In: $1^{\circ}$ CONGRESSO ACADÊMICO SOBRE MEIO AMBIENTE E DESENVOLVIMENTO DO RIO DE JANEIRO, 2004, Rio de Janeiro. Anais... Rio de Janeiro: FGV-RJ.

POSEY, D.A. Manejo de florestas secundárias, capoeiras, campos e cerrados. In: RIBEIRO, B. Suma Etnológica Brasileira. Petrópolis: Vozes, 1987.

RIBEIRO, B. Suma Etnológica brasileira. Petrópolis: Vozes, 1987.

ROMEIRO, A.R. Meio ambiente e dinâmica de inovações na agricultura. São Paulo: Fapesp/AnnaBlume, 1998.

SILVEIRA, C.T. da; FIORI, A.P.; FIORI-OKA, C. Estudo das unidades ecodinâmicas de instabilidade potencial na APA de Guaratuba: subsídios para o planejamento ambiental. Boletim Paranaense de Geociências, v.57, p.9-23, 2005.

SMEKE, I.; MORAES, C.; MARTOS, H. Impactos socioeconômicos e culturais causados pelo turismo na comunidade da vila Picinguaba. 2003. Disponível em: <http://www.puc-campinas.edu.br/pesquisa/ i semana_científica/tcc resumos/FED68C3E-52784267-8B6C-E503F5E50.pdf>. Acesso em fev. 2009.

TURNER, F. O espírito ocidental contra a natureza: mitos, história e as terras selvagens. Rio de Janeiro: Campus, 1990.

WOORTMANN, K. O trabalho da terra. Brasília: 
UnB, 1997.

WORLD WILDLIFE FUND - WWF. 2006. Disponível em: $<$ http://www.wwf.org.br $>$. Acesso em jan.

2006. 